\title{
The effects of traffic noise on tadpole behavior and development
}

\author{
Erica Castaneda ${ }^{1} \cdot$ Vernell R. Leavings $^{1} \cdot$ Reed F. Noss ${ }^{1,2} \cdot$ Molly K. Grace ${ }^{1,3}$ (D)
}

Published online: 28 January 2020

(C) The Author(s) 2020

\begin{abstract}
Traffic noise is known to negatively affect many wildlife species by interfering with foraging behavior. Frogs often lay their eggs in roadside ditches because they are predator-free, but it is possible that traffic noise could reduce the survival and fitness of tadpoles, creating an ecological trap. In a series of lab experiments, we tested whether traffic noise has a negative impact on tadpole feeding behavior, whether this is mediated by changes in tadpole activity, and whether there is any impact on tadpole growth rate or metamorphosis. Traffic noise exposure significantly reduced the amount of food consumed by Cuban Treefrog (Osteopilus septentrionalis) tadpoles. Traffic noise exposure also increased the activity level of both Southern Toad (Anaxyrus terrestris) and Cuban Treefrog tadpoles, which could possibly make them more noticeable to predators in the wild. However, these behavioral changes were not associated with changes in growth rate or timing of metamorphosis. We caution, however, that this study aimed to isolate the specific impact of traffic noise, and did not investigate other road effects that may be damaging to tadpoles.
\end{abstract}

Keywords Amphibian $\cdot$ Anthropogenic noise $\cdot$ Anuran $\cdot$ Foraging $\cdot$ Road ecology $\cdot$ Tadpole

\section{Introduction}

We have known for decades that chronic exposure to traffic noise has negative effects on human health and quality of life (Broner 1978), ranging from annoyance (Ouis 2001), to disrupted sleeping patterns (Öhrström et al. 2006), to increased risk for heart disease (Babisch 2000). Roads and their associated traffic are one of the most pervasive and obvious signatures of humans on the landscape; Riitters and Wickham (2003) estimated that less than $3 \%$ of the contiguous United States is located more than $5 \mathrm{~km}$ from a paved road, and that percentage has almost certainly shrunk since then. In fact, there are plans for a $60 \%$ increase in paved miles worldwide by 2050 (Laurance et al. 2014). It is therefore not surprising that ecologists have also been curious about how traffic noise affects wildlife.

As one might expect, traffic noise has been found to produce mainly negative outcomes for wildlife (reviewed in Francis and Barber 2013; Laurance 2015). In a study of

Molly K. Grace

molly.grace@zoo.ox.ac.uk

1 Biology Department, University of Central Florida, Orlando, FL 32828, USA

2 Present address: Florida Institute for Conservation Science, Chuluota, FL 32766, USA

3 Present address: Department of Zoology, University of Oxford, Oxford OX1 3SZ, UK woodland birds, traffic noise was the best predictor of the reduced abundance observed near roads (Reijnen et al. 1995), an effect that was reproduced empirically when traffic noise was broadcast in a roadless area (McClure et al. 2013). For individuals and species that do remain in noisy roadside areas, there can be detrimental effects. Traffic noise elevates stress levels in wood frogs (Rana sylvatica; Tennessen et al. 2014) and northern spotted owls (Strix occidentalis caurina; Hayward et al. 2011), and chronically elevated stress levels have been shown across taxa to negatively impact immune function (Martin et al. 2005), growth (Belden et al. 2005), reproduction (Ouyang et al. 2011), and survival (Pride 2005). Chronic environmental noise is associated with decreases in the quality of avian parental care (Leonard and Horn 2012; Schroeder et al. 2012). White-crowned sparrows (Zonotrichia leucophrys) exposed to traffic noise spent less time foraging and more time exhibiting vigilance behaviors, presumably because the noise interferes with their ability to detect predators (Ware et al. 2015). Species that use vocalisations as their primary form of communication (e.g. birds, frogs, many orthopterans) may find their signals masked by traffic noise, necessitating adjustments in amplitude, frequency, and/or timing (birds: Gil and Brumm 2014; frogs: Sun and Narins 2005, Bee and Swanson 2007, Cunnington and Fahrig 2010, Grace and Noss 2018; monkeys: Brumm et al. 2004). Interference with vocal communication can reduce mating success (frogs: Cunnington and Fahrig 2013; Tennessen et al. 2014). Interestingly, some species appear able 
to adapt physiologically to chronic noise, with individuals from noisy areas showing reduced stress responses relative to individuals from quiet areas (Tennessen et al. 2018). In comparison, it appears to be more difficult to adapt to the disruption in communication caused by traffic noise, with disorientation of signal receivers persisting even in individuals from noisy areas (Senzaki et al. 2018).

While most work has focused on terrestrial animals, aquatic species are not necessarily immune to the negative effects of traffic noise. Roads often pass by or over bodies of water, and the sound can be transmitted to the aquatic environment. Holt and Johnston (2015) found that low-frequency noise from truck traffic on a bridge, which potentially masks the lowfrequency signals of the Blacktail Shiner (Cyprinella venusta), propagated throughout a shallow stream further than signals of the fish, essentially creating 'dead zones' for fish communication. While Holt and Johnston's study is the first to show that traffic noise can infiltrate the aquatic environment, other anthropogenic sources of aquatic noise pollution have long been identified, and the effects on aquatic fauna are similar to what has been observed in terrestrial species (Slabbekoorn et al. 2010). Noise from passing ships induces a stress response in various fish species (Wysocki et al. 2006; Purser et al. 2016) and shore crabs (Carcinus maenas, Wale et al. 2013a). It is also known to interfere with schooling behavior in bluefin tuna (Thunnus thynnus, Sarà et al. 2007) and foraging behavior in shore crabs (Wale et al. 2013b). Aquarium noise from filters and pumps increases stress and decreases body condition of lined seahorses (Hippocampus erectus; Anderson et al. 2011).

Here, we focus on the effects of traffic noise on activity level, feeding behavior, and growth of tadpoles. Though previous studies have examined how traffic noise affects adult anurans, i.e. frogs and toads (Sun and Narins 2005; Bee and Swanson 2007; Cunnington and Fahrig 2010, 2013; Tennessen et al. 2014; Grace and Noss 2018), there have been no studies on tadpoles. The effect of traffic noise on tadpoles is relevant because some anuran species lay their eggs in roadside ditches, presumably because these ephemeral water bodies are generally free from fish predators (Mobberly and Pfrimmer 1967; Bridges and Semlitsch 2001). If traffic noise negatively affects tadpole development, however, then roadside ditches could actually be functioning as an ecological trap (Gates and Gysel 1978; Schlaepfer et al. 2002). In addition to noise, anurans have been identified as one of the taxa most vulnerable to direct mortality on roads (reviewed in Andrews et al. 2008; Fahrig and Rytwinski 2009), so gaining a more complete picture of anuran road ecology will help conservation efforts. Given the vulnerability and extinction of many amphibian species worldwide (Houlahan et al. 2000; Stuart et al. 2004), it is critical to understand which factors could contribute to their decline.
We hypothesised that, similar to what was observed in Ware et al.'s (2015) study, traffic noise would cause tadpoles to become more vigilant, altering feeding and behavior and in turn affecting growth. A similar reduction in foraging in response to noise has been observed in Mediterranean damselfish (Chromis chromis; Bracciali et al. 2012). In the presence of a predator, tadpoles from the majority of anuran species tested reduce their activity level (Lawler 1989; Richardson 2001), so we expected to observe a similar reaction to traffic noise. We predicted that if traffic noise has a negative effect on tadpole fitness, then:

1) Traffic noise exposure will decrease the amount of food consumed by tadpoles, as it has been shown to decrease foraging efficiency in other species.

2) The decrease in food consumption will be accompanied by a decrease in activity level, as we predict traffic noise will increase tadpole vigilance.

3) The combination of these factors should result in significant reduction of mass at the time of metamorphosis and/ or earlier metamorphosis, which is a signal of stress (Denver 1997; Warne et al. 2011).

\section{Materials and methods}

\section{Tadpole collection and housing}

A subset of a clutch of Cuban Treefrog (Osteopilus septentrionalis, Duméril and Bibron, 1841) tadpoles ( $n=$ 300) were collected on 7 July 2016 one day after hatching in a residential area near the University of Central Florida (Orlando, Orange County, FL). They were housed in groups of approximately 30 tadpoles in 1.9-1 (64-oz) containers filled with $10 \mathrm{~cm}$ of dechlorinated water and fed TetraMin flakes ad libitum. Water was changed every 2-3 days to prevent fouling. Because we had such a large sample of Cuban Treefrog tadpoles, individual tadpoles were not tested in more than one experiment. With the exception of the metamorphosis experiment, all testing of Cuban Treefrog tadpoles was completed before limb formation, by Gosner stage 25 of development (Gosner 1960).

Cuban treefrogs are an invasive species in Florida. Because invasive species are sometimes more physiologically resilient to stressful conditions (Jessop et al. 2013), we also collected Southern Toad (Anaxyrus terrestris, (Bonaterre, 1789)) tadpoles $(n=16)$ on 20 June 2016 at Ralph V. Chisholm Regional Park on East Lake Tohopekaliga (St. Cloud, Osceola County, FL). Tadpole age was unknown, but they were less than $1 \mathrm{~cm}$ long and had not yet developed hind limb buds (Gosner stage 25). All testing of Southern Toad tadpoles was completed before Gosner stage 25. Southern Toad 
tadpoles were housed individually in 1.9-1 food-grade plastic containers filled with $4 \mathrm{~cm}$ of dechlorinated water and fed ground TetraMin Tropical Flakes ad libitum daily. Water was changed every 2-3 days to prevent fouling. Due to the small number of individuals available, Southern Toad tadpoles were only used in one experiment.

\section{Tadpole hearing ability}

Early in development, before the development of the tympanum, tadpole hearing works in a similar fashion to that of fish, via vibrations passing through the side of their head, and react to noise (Horowitz 2012). However, they undergo a 48-h deaf period just before their forelimbs emerge in Gosner stage 41, when the developing muscle and cartilage associated with the shoulder girdle block the opening of the inner ear. Because all tadpoles in this study were tested before Gosner stage 25 (except when testing time to metamorphosis), this deaf period does not affect the results.

\section{Traffic noise stimulus}

To test tadpoles' reaction to traffic noise, we created a digital compilation of vehicle pass-by events (as in Grace and Noss 2018). The road on which the traffic noise stimulus was based is State Road 528, a highway with a speed limit of $113 \mathrm{~km} / \mathrm{h}$ (70 mph) that runs east to west through Tosohatchee Wildlife Management Area, a site rich in anuran diversity (16 documented species, including Southern Toad and Cuban Treefrog; SRCA 2010). S.R. 528 maintains a relatively high traffic volume even at night, when anurans are most likely to be calling (Fig. 1). This traffic volume remains consistent throughout the summer breeding season for anurans in Florida (March-October; Fig. 1). During the sampling time for the North American Amphibian Monitoring Program (19:00-0:00 h), average traffic volume on S.R. 528 is 1126 vehicles/h (standard deviation 476.3 vehicles/h). A study measuring the effects of road noise on the abundance of migratory birds used a playback file with 720 vehicles/h traveling at $72 \mathrm{~km} / \mathrm{h}$ (45 mph), and even at this lower traffic volume significant effects of noise were found (McClure et al. 2013).

We recorded individual vehicle pass-by events on April 30, 2015 on State Road 50, which lies just north of Tosohatchee WMA. We did not record on S.R. 528 because it was easier to pull off safely on the side of the road on S.R. 50, and also because it has a lower traffic volume, making it possible to obtain clean recordings of individual vehicles. The vehicles from which we recorded traffic noise were traveling between 97 and $113 \mathrm{~km} / \mathrm{h}$ (60 and $70 \mathrm{mph}$ ), and we recorded them at a microphone height of $1.1 \mathrm{~m}$ and at a distance of $7 \mathrm{~m}$ from the edge of the pavement. The recordings were made in WAV format using a Sennheiser MKH 50 P48 microphone with wind guard and Marantz PMD670 solid state recorder. From
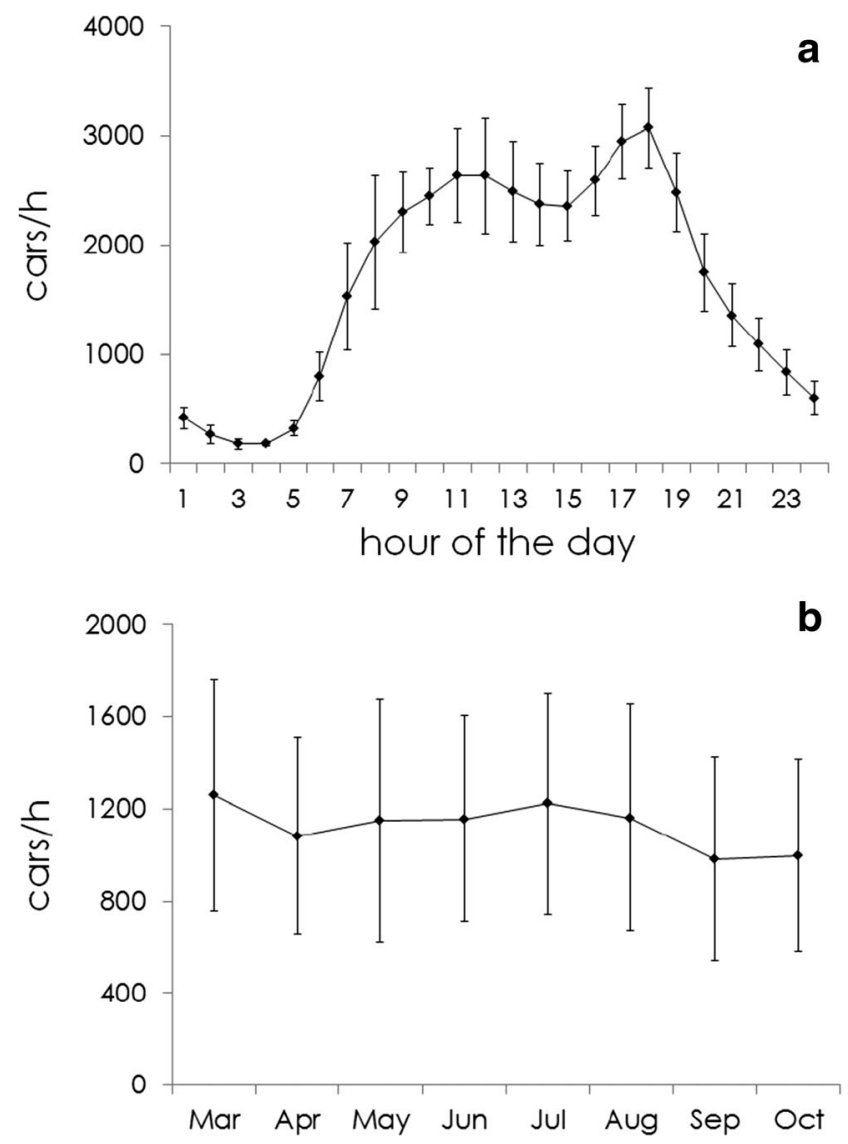

Fig. 1 Variation in traffic volume on SR 528. a Average number of vehicles observed per hour in March-October 2013 (Florida Department of Transportation statistics). Though traffic volume peaks in the middle of the day, SR 528 experiences significant traffic throughout the evening. Error bars show standard deviation. b Monthly variation in traffic volume. Average number of vehicles observed per hour on State Road 528 during time relevant to anuran calling behavior (19:00-24:00) in March-October 2013 (Florida Department of Transportation statistics). Error bars show standard deviation

our recordings, we chose 9 individual vehicle pass-by events based on the recording clarity. These pass-by events were individually normalised to a common peak amplitude in the program Audacity v. 2.1.0 (Audacity Team 2014) and combined in a repeating sound file which played back 1120 passby events per hour. This sound file was exported in WMA format because our playback equipment did not recognise files in WAV format (as in Cunnington and Fahrig 2013).

During all experiments, in the traffic noise treatment the traffic noise file was played to create an average ambient noise level of $70 \mathrm{dBA}$, which is the noise level $\sim 30 \mathrm{~m}$ from a real road (Reijnen et al. 1995). This was measured by taking sound pressure level readings in all corners of the room $(5 \times 5$ meters, and not an acoustic chamber), and adjusting the playback volume until all readings were within $\pm 2 \mathrm{~dB}$. This noise level is conservative, because some anuran species lay their eggs directly alongside the road in ditches (Mobberly and Pfrimmer 1967; Bridges and Semlitsch 2001). We checked that the 
frequencies of traffic noise were being accurately reproduced by the speaker by comparing spectrographs and power spectra of the noise recorded coming from the speakers to those from the original sound file.

\section{Effect of traffic noise on feeding behavior}

We randomly assigned 60 Cuban Treefrog tadpoles to either the traffic noise treatment $(n=30)$ or the control treatment $(n=30)$ and placed them in individual containers. The tadpoles assigned to the traffic noise treatment were moved to the experimental room, while those in the control treatment remained in the housing room. The two rooms were light- and temperature-controlled on the same schedule (temperature constant at $25^{\circ} \mathrm{C}$, lights on at 07:00 and off at 18:00 to mimic daylight hours in Orlando in July) to minimise differences in environmental conditions. Because we wished to measure changes in food consumption, we needed to be able to measure the mass of the food, and the TetraMin flakes dissolved too quickly for this to be feasible. Instead, we switched the tadpoles to a diet of boiled lettuce. Tadpoles were allowed to acclimate to their individual containers and new diet for 2 weeks.

For 4 days prior to the experiment, the tadpoles were foodstarved to ensure that they would eat during the experimental period. $48 \mathrm{~h}$ before the experiment, we measured each tadpole's body mass (gently blotted dry) so that we could correct the amount of food eaten for body size. The scale was accurate to three decimal places, so all mass measurements were rounded to three decimal places and final calculations are reported at three significant figures. On the day of the experiment, the tadpoles were given a pre-weighed amount of boiled lettuce (blotted dry) and allowed to eat ad libitum, undisturbed for $2 \mathrm{~h}$. Those in the traffic noise treatment were first exposed to the traffic noise playback file during these $2 \mathrm{~h}$, and it played continuously during the experiment. At the end of the experiment, the lettuce was weighed again and we subtracted the final mass from the original mass to determine how much lettuce had been consumed. The lettuce mostly remained in large pieces that were removed and weighed, although it is possible that we missed some small particles.

Intriguingly, we found that the lettuce samples weighed more at the end of the experiment, even though the tadpoles had clearly eaten. We discovered that the cause of this was that the lettuce absorbed water during the $2 \mathrm{~h}$ experiment. We realised that we needed to know the dry mass of the lettuce, but it was not possible to dry the lettuce samples before feeding them to the tadpoles. To account for this, we devised a method to convert the wet mass of the lettuce at both the beginning and end of the experiment to dry mass. We took freshly prepared boiled lettuce and created samples of different masses that covered the range of masses given to the tadpoles at the beginning of the experiment. We measured the wet mass, then desiccated the samples in a drying oven and measured their dry mass. We repeated this procedure with boiled lettuce samples that had soaked in water for $2 \mathrm{~h}$, mimicking the conditions at the end of the experiment.

We then plotted the wet mass against the dry mass for both data sets and fit linear, exponential, logarithmic, and power curves to determine the best fit based on $\mathrm{R}^{2}$ values. For the freshly prepared lettuce, a linear function was the best fit, while the best fit for the samples that had soaked for $2 \mathrm{~h}$ was a power function (Table 1). We used these fits and wet mass observed at the beginning and end of the experiment to calculate an estimate of the dry mass of the lettuce.

Using the fitted values, we used a one-tailed two-sample ttest to determine if traffic noise reduced food consumption by the tadpoles. Prior to performing the t-test, we checked for homogeneity of variances (F-test for equal variances, $F=$ $1.52, \mathrm{df}=29$ and $29, P=0.132$ ) and visually for normality.

\section{Effect of traffic noise on tadpole activity level: Southern Toad}

Each of the 16 tadpoles was randomly assigned to either the traffic noise treatment or control treatment (no noise) so that there were 8 tadpoles per treatment. We tested tadpoles one by one, but all tadpoles were tested on the same day. Each tadpole's container was moved from the housing room to the experimental room and the tadpole was allowed to acclimate for $1 \mathrm{~min}$. The experimental room was maintained at the same temperature as the housing room $\left(\sim 27^{\circ} \mathrm{C}\right)$. At the end of the minute, the traffic noise treatment was turned on when testing a tadpole in the non-control group. In both treatment groups, we recorded the duration of all tadpole movements using a stopwatch for $5 \mathrm{~min}$. The total summed duration of all movements was used as a measure of tadpole activity level (Richardson 2001).

Because we had such a small sample of Southern Toad tadpoles, we repeated the experiment 2 days later but switched the treatment assignments of each tadpole, allowing us to measure changes in individual behavior using a paired onetailed t-test. Prior to performing the test, we checked that the

Table $1 \quad R^{2}$ values obtained by fitting different curves to the regression of wet lettuce mass against dry lettuce mass

\begin{tabular}{lcc}
\hline Function type & $\mathrm{R}^{2}$ freshly boiled & $\mathrm{R}^{2}$ two hours \\
\hline Linear & .585 & .727 \\
Exponential & .553 & .707 \\
Logarithmic & .545 & .667 \\
Power & .567 & .732 \\
\hline
\end{tabular}


individual differences in activity between treatments (delta) were normally distributed (Shapiro-Wilk test, $W=0.918$, $P=0.156)$.

\section{Effect of traffic noise on tadpole activity level: Cuban Treefrog}

We randomly assigned 30 tadpoles each to the traffic noise and control treatment. Since the Cuban Treefrog tadpoles were housed in groups, each experimental tadpole was moved to its own container and allowed to acclimate to the container for 5 min before being moved to the experimental room. To accommodate the larger number of tadpoles being tested, tadpoles were tested six at a time (block) and videotaped, and their activity level was measured from these videos. Because we had a larger sample of Cuban Treefrog tadpoles, we did not test the same tadpoles twice. Differences in activity level were assessed using analysis of variance (ANOVA) with treatment, block, and their interaction as factors. Groups were tested for homogeneity of variances using the F test (control:treatment, $\mathrm{F}=1.51, \mathrm{df}=29$ and $29, P=0.138$; most variable block:least variable block, $\mathrm{F}=1.73$, $\mathrm{df}=11$ and $11, P=0.188$; most variable interaction:least variable interaction, $\mathrm{F}=2.47 \mathrm{df}=11$ and $11, P=0.172$ ).

\section{Effects of traffic noise on growth and time to metamorphosis}

To examine if traffic noise exposure decreased growth rate and time to metamorphosis, we assigned Cuban Treefrog tadpoles to one of four treatments: all combinations of either the traffic noise or control treatment and either a high competition or low competition treatment. We added competition as a factor because the effect of another environmental stressor, pesticides, on tadpole development is known to vary depending on the level of competition (Relyea and Diecks 2008). Tadpoles in the low-competition and high-competition treatments were kept in the same sized containers $(1.9 \mathrm{~L})$ with the same amount of water, but the number of tadpoles varied: 5 tadpoles per container in the low- competition treatment and 12 tadpoles per container in the high competition treatment. Each treatment combination was replicated 4 times for a total of 16 groups.

This experiment lasted for 3 weeks, during which time the tadpoles in the traffic noise condition were constantly exposed to the playback file. Each day, we fed each group $0.05 \mathrm{~g}$ of fish flakes. Based on average tadpole weight, this amounts to each tadpole receiving $\sim 5 \%$ of its weight in food each day in the low competition treatment and $\sim 2 \%$ in the high competition treatment. At the beginning of the experiment, all tadpoles were prior to Gosner stage 25 and were all the same age (same clutch). Every other day for 3 weeks, tadpoles were weighed to track their growth rate, and every day the groups were checked for metamorphs. We defined metamorphs as individuals that had developed all 4 limbs and were able to climb. When we removed metamorphs, we adjusted the amount of food given to each group in order to maintain the relative amount of food received by each tadpole (5\% or $2 \%$ ).

We assessed the effects of noise treatment and competition on mass at metamorphosis and day of metamorphosis using Analyses of Variance (ANOVA) with replicate as a covariate. We checked that the variances of all treatment combinations were normally distributed. Some of the groups were not normally distributed, but ANOVA remains a robust test even if this assumption is violated (Schmider et al. 2010).

\section{Results}

\section{Effect of traffic noise on feeding behavior}

Cuban Treefrog tadpoles ate on average $0.00334 \mathrm{~g}$ of food during the two-hour experiment $( \pm 0.000364 \mathrm{~g} \mathrm{SE})$. When adjusted for tadpole mass, tadpoles in the traffic noise treatment consumed less lettuce during the experiment than tadpoles in the control treatment: $0.0177 \mathrm{~g}$ lettuce/ $\mathrm{g}$ tadpole mass on average for traffic and $0.0315 \mathrm{~g}$ lettuce/ $\mathrm{g}$ tadpole mass for control (one-tailed two-sample t-test, $\mathrm{t}=3.23$, $\mathrm{df}=58, P=$ 0.00103; Fig. 2).

\section{Effect of traffic noise on tadpole activity level}

Both Southern Toad and Cuban Treefrog tadpoles were more active in the traffic noise treatment compared to the no noise control (Figs. 3, 4; Table 2). On average, Southern Toad tadpoles increased their activity by $40.2 \mathrm{~s}$ (170\% increase in activity), while Cuban Treefrog tadpoles increased activity to a lesser extent by an average of $44.7 \mathrm{~s}$ (44.1\% increase in activity).

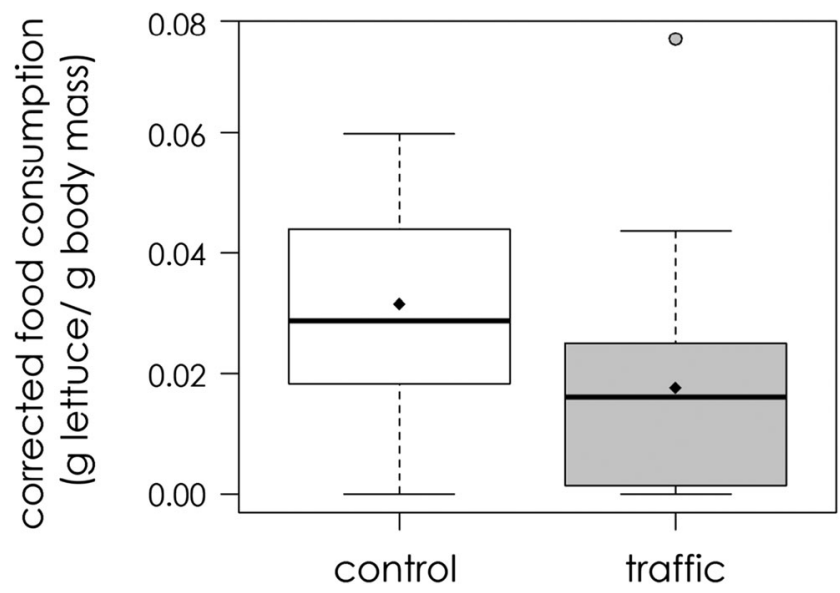

Fig. 2 Tadpoles in the control group ate significantly more than those in the traffic noise treatment. $n=30$ per treatment. The values in this figure are dry weights. Diamonds indicate group means 


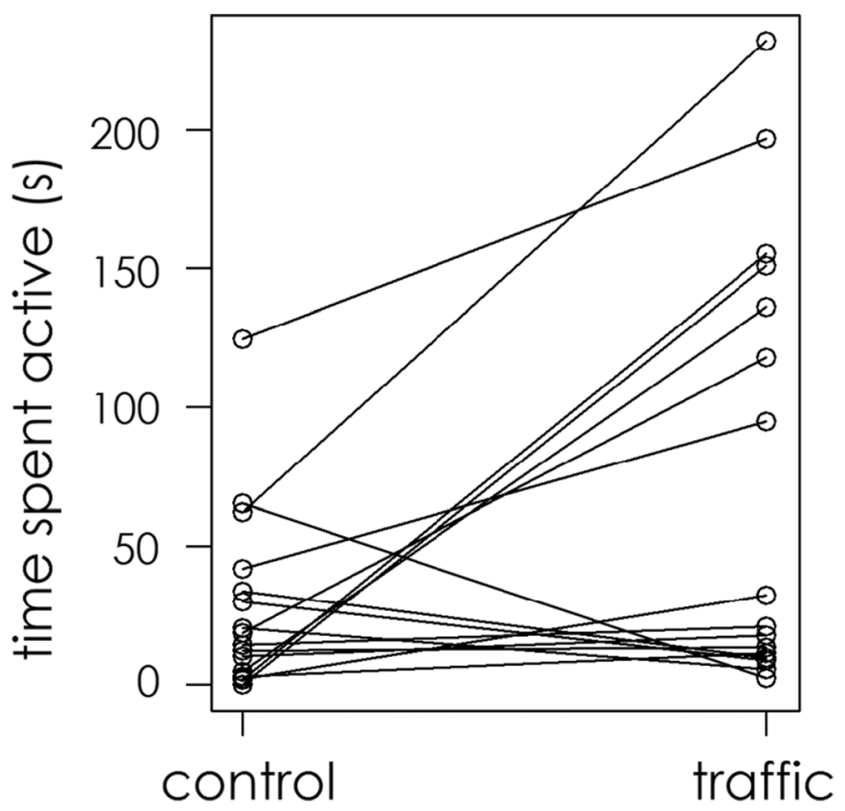

Fig. 3 Individual Southern Toad tadpoles increased activity level in response to traffic noise. Each line represents one tadpole's change in activity level from the control treatment to the noise treatment. This difference is significant (paired t-test, $\mathrm{t}=2.60, \mathrm{df}=15, n=16, P=$ $0.0101)$

\section{Effects of traffic noise on growth and time to metamorphosis}

Although traffic noise reduced food consumption in the previous experiment, this did not translate into a decreased body mass at metamorphosis (Fig. 5; Table 3). Although the interaction between treatment and competition is significant, a Tukey's post-hoc test revealed that all significant contrasts were across competition treatments. As expected, increased tadpole competition did have a negative effect on mass at metamorphosis. However, there was no significant effect of

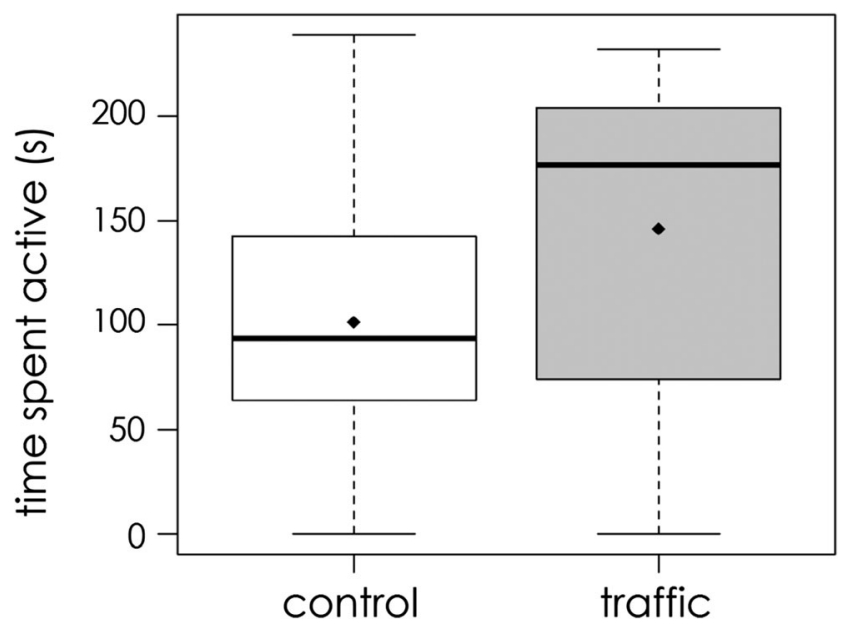

Fig. 4 Cuban Treefrog tadpoles spent more time active in the traffic noise treatment than in the control treatment (one-tailed two-sample $\mathrm{t}$-test, $\mathrm{t}=$ $2.16, \mathrm{df}=58, P=0.0173$ ). Diamonds show group means
Table 2 ANOVA table showing the effect of noise treatment on Cuban Treefrog activity level

\begin{tabular}{lrrrrl}
\hline & df & Sum Sq & Mean Sq & F & P \\
\hline Treatment & 1 & 29,987 & 29,987 & 6.09 & $0.0170^{*}$ \\
Block & 1 & 30,463 & 7616 & 1.55 & 0.203 \\
Treatment:block & 1 & 45,950 & 11,488 & 2.33 & 0.0683 \\
Residuals & 82 & 246,048 & 4921 & & \\
\hline
\end{tabular}

either traffic noise or density on day of metamorphosis (Fig. 6; Table 4).

\section{Discussion}

Although we observed that exposure to traffic noise increased tadpole activity level and decreased the amount of food consumed during an experimental trial, we did not observe any corresponding effects on timing or size at metamorphosis. This aligns with studies in cultured fish; a study of how rainbow trout (Oncorhynchus mykiss) respond to aquarium noise found no significant effects on growth rate or mortality (Wysocki et al. 2007), and a study of the effects of white noise on goldfish (Carassius auratus) found that the noise produced temporary, but not permanent, spikes in plasma cortisol (Smith et al. 2004). A possible explanation for our findings is that the brief exposure to noise in the activity and feeding experiments produced an acute spike in stress that affects behavior, but that tadpoles are able to acclimate and resume normal patterns of behavior when facing chronic exposure to noise (as their physiological responses adapt, e.g. Tennessen

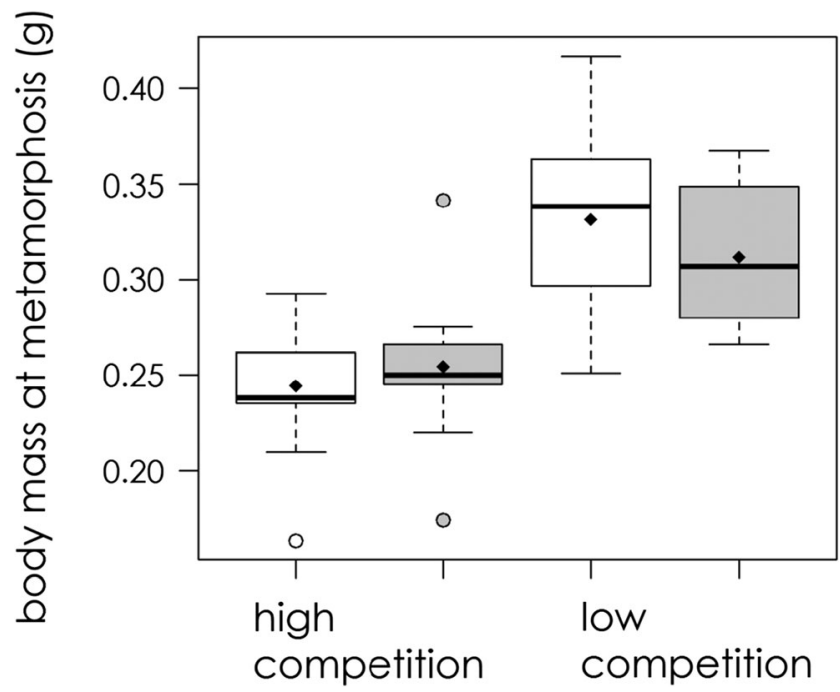

Fig. 5 Tadpole competition, but not traffic noise, has a significant effect on tadpole size at metamorphosis. White indicates control groups while gray indicates groups exposed to traffic noise. Black diamonds show means 
Table 3 ANOVA table for the effects of traffic noise and competition on tadpole size at metamorphosis

\begin{tabular}{lrllcl}
\hline & df & Sum Sq & Mean Sq & F & P \\
\hline Treatment & 1 & 0.00012 & 0.000120 & 0.111 & 0.7399 \\
Competition & 1 & 0.106 & 0.106 & 100 & $7.31 \mathrm{e}^{-16 *}$ \\
Rep & 3 & 0.0104 & 0.00346 & 3.27 & $0.0253^{*}$ \\
Treatment:competition & 1 & 0.00465 & 0.00465 & 4.39 & $0.0392^{*}$ \\
Residuals & 82 & 0.0869 & 0.00106 & & \\
\hline
\end{tabular}

et al. 2018). This could be a positive finding in terms of anuran conservation, but several caveats must be addressed.

Most anuran species decrease their activity level in the presence of a predator or predator cues (Lawler 1989; Richardson 2001), but some species (across the anuran families Bufonidae, Ranidae, and Hylidae) show increased activity, so our finding that both Cuban Treefrogs and Southern Toads increased their time spent active in response to traffic noise is not unprecedented. However, though we hypothesised that traffic noise would induce similar responses in the tadpoles as a predator would, our experiment did not include any actual predators. Previous work has shown that tadpoles with higher activity levels were less likely to survive in the presence of a predator (Lawler 1989), so it is possible that increased activity in response to traffic noise could make tadpoles more vulnerable to predation. Chan et al. (2010) found that Caribbean hermit crabs (Coenobita clypeatus) allowed a simulated predator to approach closer under conditions of anthropogenic noise. However, our experiment did not test for this.

Another caveat that limits extrapolation from our results is that, due to the difficulty in obtaining tadpoles, we only tested one clutch of tadpoles for each species. While a clutch of Cuban Treefrog tadpoles provides more than enough

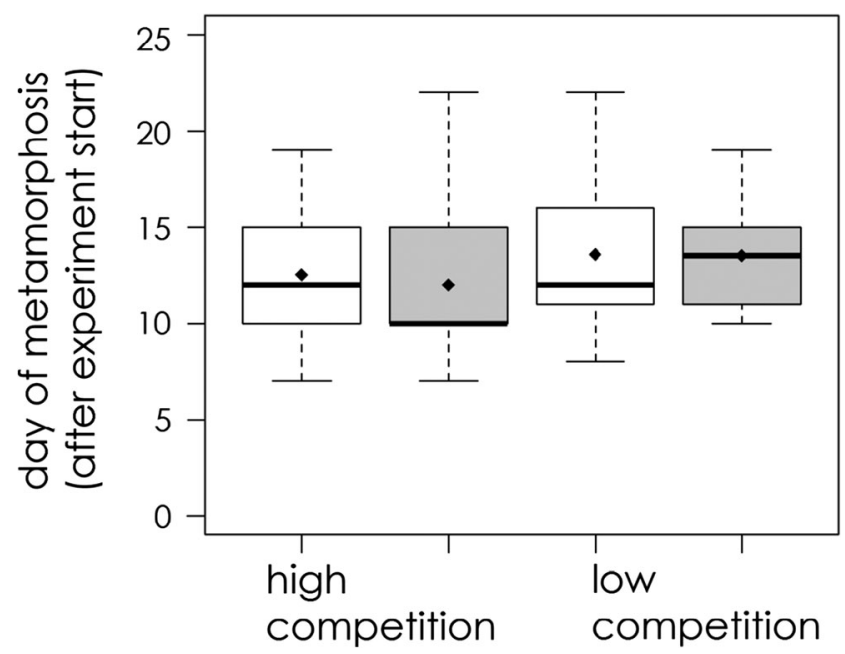

Fig. 6 No effect of competition or traffic noise treatment on the timing of metamorphosis. White indicates control groups while gray indicates groups exposed to traffic noise. Black diamonds show means
Table 4 ANOVA table for the effects of traffic noise and competition on day of metamorphosis

\begin{tabular}{lrccll}
\hline & df & Sum Sq & Mean Sq & F & P \\
\hline Treatment & 1 & 3.3 & 3.3 & 0.275 & 0.601 \\
Density & 1 & 33.4 & 33.4 & 2.78 & 0.0991 \\
Rep & 3 & 58.2 & 19.4 & 1.62 & 0.192 \\
Treatment:density & 1 & 0.5 & 0.54 & 0.045 & 0.833 \\
Residuals & 82 & 983 & 12.0 & & \\
\hline
\end{tabular}

individuals to achieve statistical power in multiple experiments, an experiment where all individuals come from the same clutch is pseudoreplicated. That is, it is possible that the behavioral responses were a quirk of this particular clutch and not a general pattern for the species as a whole. The fact that similar results were found when we tested the activity level of Southern Toad tadpoles helps alleviate this concern, but it is a definite limitation to this set of experiments.

\section{Conclusion}

In summary, we did not find that traffic noise had a negative impact on tadpole fitness at metamorphosis, as measured by size at and timing of metamorphosis. Therefore, our findings provide no evidence that traffic noise makes the use of roadside ditches as egg deposition sites by anurans an ecological trap in terms of tadpole growth; however, it is important to note that these results were obtained by testing a very successful invader, the Cuban Treefrog. We did find that tadpoles of both species, the native Southern Toad and the invasive Cuban Treefrog, increased activity levels in response to noise. Going forward, it will be crucial to empirically investigate the potential interaction between traffic noise and predation, mediated by increased activity levels in response to noise, before concluding that traffic noise does not produce negative outcomes for tadpoles.

Acknowledgements Many thanks to C. Parkinson, who helped greatly in the set-up of husbandry and experimental premises, and to Consolidated Plastics Company and TetraMin for providing materials free of charge to a poor graduate student. The use of animals described in this manuscript was approved by the University of Central Florida's Institutional Animal Care and Use Committee under protocol \#15-11 W. The Florida Fish and Wildlife Conservation Commission did not require permits for this use of tadpoles after carefully reviewing our application.

Open Access This article is licensed under a Creative Commons Attribution 4.0 International License, which permits use, sharing, adaptation, distribution and reproduction in any medium or format, as long as you give appropriate credit to the original author(s) and the source, provide a link to the Creative Commons licence, and indicate if changes were made. The images or other third party material in this article are included in the article's Creative Commons licence, unless indicated otherwise in a credit line to the material. If material is not included in the article's 
Creative Commons licence and your intended use is not permitted by statutory regulation or exceeds the permitted use, you will need to obtain permission directly from the copyright holder. To view a copy of this licence, visit http://creativecommons.org/licenses/by/4.0/.

\section{References}

Anderson PA, Berzins IK, Fogarty F, Hamlin HJ, Guillette LJ (2011) Sound, stress, and seahorses: the consequences of a noisy environment to animal health. Aquaculture 311:129-138

Andrews KM, Gibbons JW, Jochimsen DM, Mitchell J (2008) Ecological effects of roads on amphibians and reptiles: a literature review. Herpetol Conserv 3:121-143

Audacity Team (2014) Audacity: free audio editor and recorder. Version 2.1.0 retrieved April 3th 2015 from http://audacity.sourceforge.net/

Babisch W (2000) Traffic noise and cardiovascular disease: epidemiological review and synthesis. Noise Health 2:9-32

Bee MA, Swanson EM (2007) Auditory masking of anuran advertisement calls by road traffic noise. Anim Behav 74(6):1765-1776

Belden LK, Moore IT, Wingfield JC, Blaustein AR (2005) Corticosterone and growth in Pacific treefrog (Hyla regilla) tadpoles. Copeia 2005: 424-430

Bracciali C, Campobello D, Giacoma C, Sarà G (2012) Effects of nautical traffic and noise on foraging patterns of Mediterranean damselfish (Chromis chromis). PloS One 7(7):e40582

Bridges CM, Semlitsch RD (2001) Genetic variation in insecticide tolerance in a population of southern leopard frogs (Rana sphenocephala): implications for amphibian conservation. Copeia 2001(1):7-13

Broner N (1978) The effects of low frequency noise on people-A review. J Sound Vib 58(4):483-500

Brumm H, Voss K, Köllmer I, Todt D (2004) Acoustic communication in noise: regulation of call characteristics in a New World monkey. $\mathrm{J}$ Exp Biol 207(3):443-448

Chan AAYH, Giraldo-Perez P, Smith S, Blumstein DT (2010) Anthropogenic noise affects risk assessment and attention: the distracted prey hypothesis. Biol Lett 6(4):458-461

Cunnington GM, Fahrig L (2010) Plasticity in the vocalizations of anurans in response to traffic noise. Acta Oecol 36(5):463-470

Cunnington GM, Fahrig L (2013) Mate attraction by male anurans in the presence of traffic noise. Anim Conserv 16(3):275-285

Denver RJ (1997) Environmental stress as a developmental cue: corticotropin-releasing hormone is a proximate mediator of adaptive phenotypic plasticity in amphibian metamorphosis. Horm Behav 31(2):169-179

Fahrig, L. And T. Rytwinski. 2009. Effects of roads on animal abundance: an empirical review and synthesis. Ecol Soc 14(1):21.

Francis C, Barber JR (2013) A framework for understanding noise impacts on wildlife: an urgent conservation priority. Front Ecol Environ 11(6):305-313

Gates JE, Gysel LW (1978) Avian nest dispersion and fledging success in field-forest ecotones. Ecology 59:871-883

Gil D, Brumm H (2014) Acoustic communication in the urban environment: patterns, mechanisms, and potential consequences of avian song adjustments. In: Gil D, Brumm H (eds) Avian urban ecology. Oxford University Press, UK, pp 69-83

Grace MK, Noss RF (2018) Evidence for selective avoidance of traffic noise by anuran amphibians. Anim Conserv 21(4):343-351

Hayward LS, Bowles AE, Ha JJ, Wasser SK (2011) Impacts of acute and long-term vehicle exposure on physiology and reproductive success of the northern spotted owl. Ecosphere 2:art65

Holt DE, Johnston CE (2015) Traffic noise masks acoustic signals of freshwater stream fish. Biol Conserv 187:27-33
Horowitz SS (2012) The universal sense: how hearing shapes the mind. Bloomsbury Publishing, USA

Houlahan JE, Findlay CS, Schmidt BR, Meyer AH, Kuzmin SL (2000) Quantitative evidence for global amphibian population declines. Nature 404:752-755

Jessop TS, Letnic M, Webb JK, Dempster T (2013) Adrenocortical stress responses influence an invasive vertebrate's fitness in an extreme environment. Proc R Soc B 280(1768):20131444

Laurance WF (2015) Wildlife struggle in an increasingly noisy world. Proc Natl Acad Sci U S A 112:11995-11,996

Laurance WF, Clements GR, Sloan S, O'Connell CS, Mueller ND, Goosem M, Venter O et al (2014) A global strategy for road building. Nature 513:229-232

Lawler SP (1989) Behavioral responses to predators and predation risk in four species of larval anurans. Anim Behav 38:1039-1047

Leonard ML, Horn AG (2012) Ambient noise increases missed detections in nestling birds. Biol Lett 8(4):530-532

Martin LB, Gilliam J, Han P, Lee K, Wikelski M (2005) Corticosterone suppresses cutaneous immune function in temperate but not tropical house sparrows, Passer domesticus. Gen Comp Endocrinol 140: $126-135$

McClure CJW, Ware HE, Carlisle J, Kaltenecker G, Barber JR (2013) An experimental investigation into the effects of traffic noise on distributions of birds: avoiding the phantom road. Proc R Soc B 280(1773):20132290

Mobberly WC Jr, Pfrimmer RJ (1967) Distribution of crawfish in a roadside ditch. Am Midl Nat 78:82-88

Öhrström E, Hadzibajramovic E, Holmes M, Svensson H (2006) Effects of road traffic noise on sleep: studies on children and adults. J Environ Psychol 26:116-126

Ouis D (2001) Annoyance from road traffic noise: a review. J Environ Psychol 21:101-120

Ouyang JQ, Sharp P, Dawson A, Quetting M, Hau M (2011) Hormone levels predict individual differences in reproductive success in a passerine bird. Proc R Soc B 278:2537-2545

Pride RE (2005) High faecal glucocorticoid levels predict mortality in ring-tailed lemurs (Lemur catta). Biol Lett 1:60-63

Purser J, Bruintjes R, Simpson SD, Radford AN (2016) Conditiondependent physiological and behavioral responses to anthropogenic noise. Physiol Behav 155:157-161

Reijnen R, Foppen R, Braak CT, Thissen J (1995) The effects of car traffic on breeding bird populations in woodland III Reduction of density in relation to the proximity of main roads. J Appl Ecol 32: 187-202

Relyea RA, Diecks N (2008) An unforeseen chain of events: lethal effects of pesticides on frogs at sublethal concentrations. Ecol Appl 18(7): $1728-1742$

Richardson JML (2001) A comparative study of activity levels in larval anurans and response to the presence of different predators. Behav Ecol 12:51-58

Riitters KH, Wickham JD (2003) How far to the nearest road? Front Ecol Environ 1(3): 125-129

Sarà G, Dean JM, D'Amato D, Buscaino G, Oliveri A, Genovese S, Ferro $S$ et al (2007) Effect of boat noise on the behavior of bluefin tuna Thunnus thynnus in the Mediterranean Sea. Mar Ecol Prog Ser 331(2007):243-253

Schlaepfer MA, Runge MC, Sherman PW (2002) Ecological and evolutionary traps. Trends Ecol Evol 17(10):474-480

Schmider E, Ziegler M, Danay E, Beyer L, Bühner M (2010) Is it really robust? Reinvestigating the robustness of ANOVA against violations of the normal distribution assumption. Methodology 6(4): $147-151$

Schroeder J, Nakagawa S, Cleasby IR, Burke T (2012) Passerine birds breeding under chronic noise experience reduced fitness. PLoS One 7(7):e39200 
Seminole Ranch Conservation Area (2010) Seminole ranch conservation area land management plan. Mims, FL.

Senzaki M, Kadoya T, Francis CD, Ishiyama N, Nakamura F (2018) Suffering in receivers: negative effects of noise persist regardless of experience in female anurans. Funct Ecol 32(8):2054-2064

Slabbekoorn H, Bouton N, van Opzeeland I, Coers A, ten Cate C, Popper AN (2010) A noisy spring: the impact of globally rising underwater sound levels on fish. Trends Ecol Evol 25(7):419-427

Smith ME, Kane AS, Popper AN (2004) Noise-induced stress response and hearing loss in goldfish (Carassius auratus). J Exp Biol 207(3): $427-435$

Stuart SN, Chanson JS, Cox NA, Young BE, Rodrigues AS, Fischman DL, Waller RW (2004) Status and trends of amphibian declines and extinctions worldwide. Science 306:1783-1786

Sun JW, Narins PM (2005) Anthropogenic sounds differentially affect amphibian call rate. Biol Conserv 121(3):419-427

Tennessen JB, Parks SE, Langkilde T (2014) Traffic noise causes physiological stress and impairs breeding migration behavior in frogs. Conserv Physiol 2(1):cou032

Tennessen JB, Parks SE, Swierk L, Reinert LK, Holden WM, RollinsSmith LA, Walsh KA, Langkilde T (2018) Frogs adapt to physiologically costly anthropogenic noise. Proc R Soc B 285(1891):20182194

Wale MA, Simpson SD, Radford AN (2013a) Size-dependent physiological responses of shore crabs to single and repeated playback of ship noise. Biol Lett 9:20121194

Wale MA, Simpson SD, Radford AN (2013b) Noise negatively affects foraging and antipredator behavior in shore crabs. Anim Behav 86: $111-118$

Ware HE, McClure CJW, Carlisle JD, Barber JR (2015) A phantom road experiment reveals traffic noise is an invisible source of habitat degradation. Proc Natl Acad Sci U S A 112:12105-12,109

Warne RW, Crespi EJ, Brunner JL (2011) Escape from the pond: stress and developmental responses to ranavirus infection in wood frog tadpoles. Funct Ecol 25(1):139-146

Wysocki LE, Dittami JP, Ladich F (2006) Ship noise and cortisol secretion in European freshwater fishes. Biol Conserv 128(4):501-508

Wysocki LE, Davidson JW, Smith ME, Frankel AS, Ellison WT, Mazik PM, Popper AN, Bebak J (2007) Effects of aquaculture production noise on hearing, growth, and disease resistance of rainbow trout Oncorhynchus mykiss. Aquaculture 272(1):687-697 